\title{
Effectiveness and Safety of Botulinum Toxin Type $A$ in Children with Musculoskeletal Conditions: What Is the Current State of Evidence?
}

\author{
Noémi Dahan-Oliel, ${ }^{1}$ Bahar Kasaai, ${ }^{1}$ Kathleen Montpetit, ${ }^{1}$ and Reggie Hamdy ${ }^{1,2}$ \\ ${ }^{1}$ Shriners Hospital for Children-Canada, Montreal, QC, Canada H3G 1 A6 \\ ${ }^{2}$ Division of Orthopaedic Surgery, McGill University, Montreal, QC, Canada H3G 1 Y6
}

Correspondence should be addressed to Reggie Hamdy, rhamdy@shriners.mcgill.ca

Received 3 November 2011; Accepted 29 January 2012

Academic Editor: Namik Yaşar Özbek

Copyright (C) 2012 Noémi Dahan-Oliel et al. This is an open access article distributed under the Creative Commons Attribution License, which permits unrestricted use, distribution, and reproduction in any medium, provided the original work is properly cited.

\begin{abstract}
Children with musculoskeletal conditions experience muscle weakness, difficulty walking and limitations in physical activities. Standard treatment includes physiotherapy, casting, and surgery. The use of botulinum toxins appears as a promising treatment on its own, but usually as an adjunct to other treatment modalities and as an alternative to surgery. The objectives were to establish the evidence on the effectiveness, safety and functional outcome of BTX-A in children with musculoskeletal conditions. A literature search using five electronic databases identified 24 studies that met our inclusion criteria. Two randomized clinical trials were included; most studies were case studies with small sample sizes and no control group. Improvements in gait pattern, function, range of motion, reduction of co-contractions, and avoidance of surgical procedures were found following BTX-A injections. Adverse events were not reported in 10 studies, minor adverse events were reported in 13 children and there were no severe adverse events. Additional doses appear safe. BTX-A is a promising treatment adjunct in improving functional outcomes in children with musculoskeletal conditions. Future studies including larger samples, longer follow-up periods and a comparison group are required to provide evidence on the effectiveness and safety of this drug in children with musculoskeletal conditions.
\end{abstract}

\section{Introduction}

Thousands of children and adolescents across the United States suffer from musculoskeletal conditions each year $[1,2]$. Common musculoskeletal conditions in children include cerebral palsy (CP), congenital muscular torticollis (CMT), Duchenne muscular dystrophy, idiopathic clubfoot, idiopathic toe walking (ITW), Legg-Calvé-Perthes disease (LCPD), limb length discrepancy, and neonatal brachial plexus palsy (NBPP). Musculoskeletal abnormalities and deformities can deprive children of physical activities, childhood experiences, and a healthy lifestyle. Besides the physical and psychosocial burden these conditions and injuries place on the child and family, these conditions also incur a financial burden for the patient and the healthcare system as multiple hospital visits are often required.

Proper and timely treatment including standard approaches such as physiotherapy, casting, bracing, and surgery is essential to ensure the child optimal growth and development. Besides these traditional modalities, the use of botulinum toxins appears as a promising treatment on its own, as an adjunct to other treatment modalities and as an alternative to surgery. Several authors have suggested the use of BTX-A in children with musculoskeletal conditions, yet the evidence supporting its safety and effectiveness is not well established. The use of BTX-A in children with $\mathrm{CP}$ has been widely documented [3-5] and is beyond the scope of this paper. The objectives of this systematic review were to establish the evidence on the effectiveness, safety, and functional outcome of BTX-A in children with musculoskeletal conditions.

1.1. Mechanisms of Action of Botulinum Toxins. Botulinum toxin is an extremely potent, naturally occurring poison resulting from the fermentation of the anaerobic sporeforming bacterium Clostridium botulinum. These toxins 
cause flaccid paralysis by blocking acetylcholine release, which is required for muscle contraction at the neuromuscular junction. Thus, the toxins have the capacity to reduce muscular activity in a dose-dependent manner. Muscle weakness occurs within a few days to one week after local injection, peaks within two weeks for several weeks, and then plateaus in milder form (the desired clinical effect) before gradually returning to baseline [6]. Clinically, this chemodenervation with muscle relaxation lasts between 12 and 16 weeks [7]. Recovery from the toxin-induced paralysis begins with resprouting of axon terminals and slow recovery of the neurons ability to release acetylcholine, which results in nerve conduction to be reestablished.

Clinical observations suggest that these neurotoxins have three mechanisms of action: paralytic, antisecretory, and analgesic (antinociceptive). A number of studies suggest that several pathways play a role in the analgesic effects of botulinum toxins, such as in conditions of pathologic muscle overactivity (dystonia and spasticity) [8] and in the role of the calcitonin gene-related peptide in the afferent signaling of pain [9]. The most effective dose is unknown although recommendations have been given [10]. The FDA has approved a total-body dose of 400 units administered every 12 to 16 weeks or at longer intervals to avoid toxicity. Identifying the appropriate muscle sites for injection is done through palpation, electrical stimulation, electromyography, ultrasound, fluoroscopy, and computerized tomography depending on the muscle size and location. A needle between 23 and 27 gauge is selected based on muscle depth, difficulty palpating the muscle, and use of electromyography. Injections may be administered under local anesthesia, conscious sedation, or general anesthesia [11].

1.2. Botulinum Toxin Serotypes. There are seven different serotypes of the neurotoxin, named botulinum toxin (BTX) types A to G. Although they all inhibit acetylcholine release from nerve terminals, they differ according to their intracellular protein targets, potency, dosing, and duration of effect. BTX-A is the serotype that has been most studied in terms of therapeutic application. BTX-B and BTX-F have also been used in clinical practice, but are less potent than BTX-A, and have a shorter duration of action [12]. BTX-B has also been shown to have regional and systemic anticholinergic adverse side effects, which limits its clinical use [4].

There are currently three types $\mathrm{A}$ and one type $\mathrm{B}$ brand of botulinum toxins available in the US market. In 2010, the US Food and Drug Administration (FDA) announced generic names for all of the versions of injectable botulinum toxins. This change in terminology is expected to differentiate between these different brands and provide each brand with its own identity thereby improving its clinical use and reducing errors and misinterpretation. Hence, OnabotulinumtoxinA (Botox by Allergan INC in the United States), AbobotulinumtoxinA (Dysport by Ipsen in France), IncobotulinumtoxinA (Xeomin by Merz Pharmaceuticals $\mathrm{GmbH}$ in Germany), and RimabotulinumtoxinB (Myobloc/Neurobloc by Solstice Neurosciences in the United States) are the new four generic names used in the USA.
These new generic names have not yet been adopted by other regulatory agencies [13].

1.3. Clinical Use of Botulinum Toxin Type A. BTX-A was first approved by the FDA in 1989 for the treatment of strabismus and blepharospasm (two eye muscle disorders), making it the first botulinum toxin type A product approved in the world. In the USA, BTX-A is also approved to treat cervical dystonia and severe primary axillary hyperhidrosis in adults [13]. Recently, the FDA has also approved the use of BTXA to treat increased muscle stiffness in the elbow, wrist, and finger muscles in adults with upper limb spasticity. In addition to its therapeutic uses, the same formulation of BTX-A was approved by the FDA in 2002 under the trade name Botox Cosmetic to improve the look of facial wrinkles in adults less than 65 years of age. BTX-A is one of the most widely researched medicines in the world.

Although the use of BTX-A has not yet been approved for use in children, it has been used in a variety of clinical conditions both for its neuromuscular and analgesic effects due to its safe, predictable, and reversible effects on motor weakness. These off-label indications include CMT, CP, idiopathic clubfoot, ITW, LCPD, lower limb lengthening and NBPP [14]. BTX-A is used in these children to decrease spasticity, manage postoperative pain, and improve quality of life. The most common use of BTX-A in children is for the treatment of spasticity in CP [15]. Studies have shown that BTX-A decreases muscle tone in children with upper and lower limbs spasticity associated with CP [4] and can help prevent the development of muscle contractures and bony deformities [16], as well as improve upper limb movement and function [15-17]. Patient selection, BTX-A dosing, dilution and administration, identification of muscle groups, and outcome measurement must be carefully considered $[13,16]$.

1.4. Adverse Events. Adverse events following botulinum toxin injection have been found to be mild, temporary, as well as dose and site related [12]. These may include local reactions, such as bruising and pain at the site of injection, excessive localized muscle weakness, and incontinence. Systemic effects are very rare [18] and may include flulike symptoms, headaches, light-headedness, fever, chills, hypertension, diarrhea and abdominal pain, generalized weakness, dysphagia, dry mouth, and subsequent aspiration. These are far less common, are generally short-lived, and may result from the systemic spread of the toxin to adjacent muscles. A boxed warning label describing the spread of the toxin and its potentially life-threatening effects appears on the labels following the death of a child following BTXA injections [13]. However, until today, no causal relationship confirmed the evidence relating this specific adverse event to the toxins [14]. Caution should be exerted when injecting BTX-A in children with preexisting swallowing or respiratory problems. Since all botulinum neurotoxins are proteins, immunoresistance may develop secondary to antibody formation. The incidence of antibody-mediated resistance in long-term treated patients ranges from 3 to 
$23 \%$, depending on the patient sample, treatment regimen and toxin preparation [7]. A recent Australian study [19] prospectively documented the presence of adverse events in 334 children with $\mathrm{CP}$ in the month before and in the month after BTX-A injection. They found that the children had significant morbidities prior to the injection, adverse events were present in $23.2 \%$ of children, and no deaths occurred.

1.5. Congenital Muscular Torticollis. CMT is common and refers to unilateral contracture of the sternocleidomastoid muscle that restricts the infant's range of motion at the neck. Infants with CMT display head tilt toward the shortened side, which is often combined with rotation of the head to the opposite side $[20,21]$. It is reported to occur in 1 infant in every 250-300 live births [21, 22]. Manual stretching is still the most common form of treatment, and about $90 \%$ of CMT resolves with stretching exercises [22]. When conservative treatment is ineffective, surgery is considered. However, as an alternative to invasive surgical intervention, BTX-A may be an option to increase the effectiveness of stretching on the side of the contracture and allow strengthening of overstretched and weakened muscles on the opposite side of the neck $[12,21,22]$.

1.6. Duchenne Muscular Dystrophy. It is a progressive Xlinked recessive disorder and is caused by a defective gene for dystrophin affecting approximately 1 out of every 3,600 male infants. Muscle tissue is replaced by adipose and connective tissue [23]. The proximal muscles of the lower extremities are affected first, with decreased range of motion, flexion contracture of the hip and knee, and extension contracture of the ankle. Symptoms usually appear before age 6 and typically include fatigue, muscle weakness, and progressive difficulty in walking. Braces may improve mobility and selfcare function, and a wheelchair is often used by age 12. There is no known cure for Duchenne muscular dystrophy and by the late teens or twenties the condition is severe enough to shorten life expectancy. Treatment aims to control symptoms to maximize quality of life and maintain muscle strength and function. BTX-A may be indicated to decrease muscle contractures of the lower extremities and facilitate standing and mobility [14].

1.7. Idiopathic Clubfoot. In this congenital deformity, the hindfoot is in equinovarus and the midfoot and forefoot are adducted and supinated. Approximately $50 \%$ of cases of clubfoot are bilateral. The exact etiology remains unknown, although numerous factors have been implicated. Clubfoot is one of the most common birth defects, occurring in 1-3 per 1000 live births. A child with an untreated clubfoot will walk on the outer edge of the foot instead of the sole, develop painful callosities, be unable to wear shoes, and have painful feet that often limit activity. Nonsurgical modalities include serial manipulation and casting, such as Ponseti's technique $[24,25]$, as well as taping, physical therapy, and continuous passive motion. Surgery is indicated if satisfactory clinical and radiographic correction by nonsurgical methods is not obtained. BTX-A injection into the child's calf muscle is indicated to facilitate nonsurgical techniques, to supplement surgical release and to serve as an alternative to Achilles tendon lengthening by reducing the tone in the most contracted muscles $[12,14]$.

1.8. Idiopathic Toe Walking. This condition is present in children older than 3 years of age still walking on their toes without any neurological, orthopaedic, or psychiatric diseases. ITW has been estimated to occur in 7 to $24 \%$ of the childhood population [26]. Treatment recommendations include physical therapy, casting, bracing, surgical release, and Achilles tendon lengthening [14]. BTX-A may be useful to manage the contractures in cases in which toe walking recurs despite conservative and surgical treatment.

1.9. Legg-Calvé-Perthes Disease. LCPD is a degenerative disease of the hip joint affecting about 10.8 children of 100,000 children and is more common in boys [27]. It is characterized by an interruption of the blood supply of the head of the femur with loss of bone mass and joint deformity at the hip. The disease is typically found in young children, and it can lead to osteoarthritis in adults. Common symptoms include hip, knee, or groin pain, exacerbated by hip/leg movement, reduced range of motion at the hip and painful and limping gait. Physical activity such as standing, walking, running, and kneeling may cause severe irritation or inflammation of the damaged area. The goal of treatment is to prevent deformity of the femoral head [27] and avoid severe degenerative arthritis later on. BTX-A may be indicated to weaken selected muscles to restore muscle balance at the hip joint [14].

1.10. Lower Limb Lengthening. Children undergoing lower limb lengthening using an external fixator exhibit excellent results in most cases, yet the postoperative pain can be significant and often requires prolonged use of analgesics and even narcotics $[28,29]$. Other aspects of the limb lengthening, such as the osteotomy and incision sites, gradual distraction increasing soft tissue tension, range of motion exercises, and gait training result in ongoing pain for weeks after the application. Appropriate pain management is essential for optimal quality of life and functional outcomes in children undergoing limb lengthening. BTXA has been shown to reduce postoperative pain in children secondary to reduced muscle spasm [12] and may be indicated in children undergoing lower limb lengthening to alleviate spasm and pain during the lengthening process.

1.11. Neonatal Brachial Plexus Palsy. NBPP is defined as a flaccid paresis of the upper extremity secondary to unwanted muscular cocontraction or inappropriate activation of antagonist muscles due to increased forces of distraction to the neck during delivery. Associated injuries may include fractures to the clavicle and humerus, facial nerve palsy, and torticollis. Incidence varies between 0.38 and 3 per 1000 live births in industrialized countries and occurs more frequently in infants born over $4 \mathrm{~kg}$, breech deliveries, maternal diabetes, and vacuum/forceps extraction [30]. While early 
physical therapy yields complete return to function in many infants, infants whose elbow flexion and shoulder abduction have not recovered before 6 months are indicated for surgical reconstruction of the brachial plexus [30]. A novel approach for children with NBPP injuries is the therapeutic use of BTX-A to inhibit unwanted cocontractions and activate antagonist muscles. Early treatment of these children with BTX-A injections may also result in stronger, normal muscles and may prevent the development of glenoid dysplasia $[12,31]$.

\section{Materials and Methods}

A literature search using the electronic databases MEDLINE, PubMed, Cochrane, Trip, and Web of Science for published articles in English from 1980 to September 2011 was conducted using botulinum toxin, congenital muscular torticollis, Duchenne muscular dystrophy, idiopathic clubfoot, idiopathic toe walking, Legg-Calvé-Perthes disease, lower limb lengthening, neonatal brachial plexus palsy, and relevant search terms. To be included, a study had to be written in English and to include children between 0 to 21 years of age with one of the above-mentioned musculoskeletal conditions. Review articles, editorials, commentaries, and conference proceedings were excluded. Research studies that were included in this review were classified as levels I to IV, based on the American Academy of Neurology (AAN) levels of evidence. Data was independently extracted by two reviewers (N. Dahan-Oliel and B. Kasaai).

\section{Results}

3.1. Search Results. The literature search yielded 791 hits, which were then reviewed for eligibility. Twenty-four studies met our inclusion criteria and were included in this review. A flow chart illustrates the search results in Figure 1. The majority of studies were on children with NBPP $(n=10)$, followed by idiopathic clubfoot $(n=5)$, CMT $(n=4)$, ITW $(n=3)$, Duchenne muscular dystrophy $(n=1)$, and lower limb lengthening $(n=1)$. No studies that looked at the effect of BTX-A in children with LCPD were found. Findings are categorized by musculoskeletal condition and are summarized in Table 1.

3.2. Congenital Muscular Torticollis. Four studies were included. Two of these studies [32, 33] included both children and adults but were included as separate results for children were provided. In total, outcome was provided for fortyfive children aged 3 months to 18 years following BTX-A injections. The following muscles were injected in isolation or in combination: sternocleidomastoid, trapezius, splenius, and scalenus. Head posture, cervical ROM, and pain were most frequently assessed. Improvement was reported in 36 patients $(80 \%)$. Adverse events were not reported in two studies $[32,33]$. Two studies reported mild dysphagia, neck weakness, neck bruising and soreness, and brief fever following injection in five children $[34,35]$. There were variations in BTX-A dosage, number of injections per muscle, length

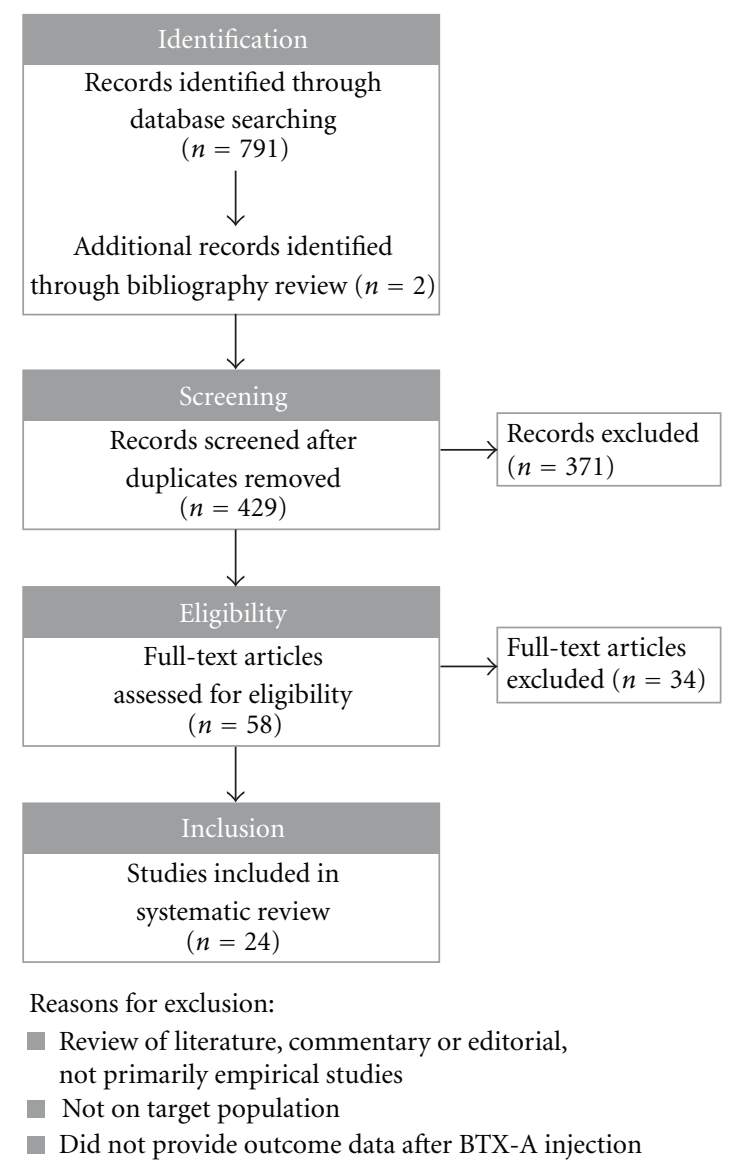

Figure 1

of follow-up, and outcomes assessed between studies as well as within the same study, which limited comparability of findings. Standardized outcome measures were not used. It is difficult to attribute clinical improvements to the BTX-A treatment since the children in these studies often received a combination of both BTX-A injections and physical therapy. Furthermore, none of these studies compared BTXA treatment with either traditional treatment or surgical treatment. One study on 15 infants who had a significant risk of progressing to surgery because of severe torticollis found promising results. Indeed, only the oldest infant required surgical release following BTX-A injections, while the other 14 infants showed significantly improved neck ROM and did not require surgery [35]. These findings suggest that BTX-A may be a safe and effective treatment modality when traditional treatments (home program, physical therapy) do not yield acceptable results. BTX-A treatment may obviate surgical interventions in certain cases [35], but randomized controlled trials with larger samples are needed to confirm this finding. Although it seems that the initial injections of BTX-A should be administered at a young age, the exact age is not yet established.

3.3. Duchenne Muscular Dystrophy. One study met the inclusion criteria [36]. An 11-year-old boy was injected 


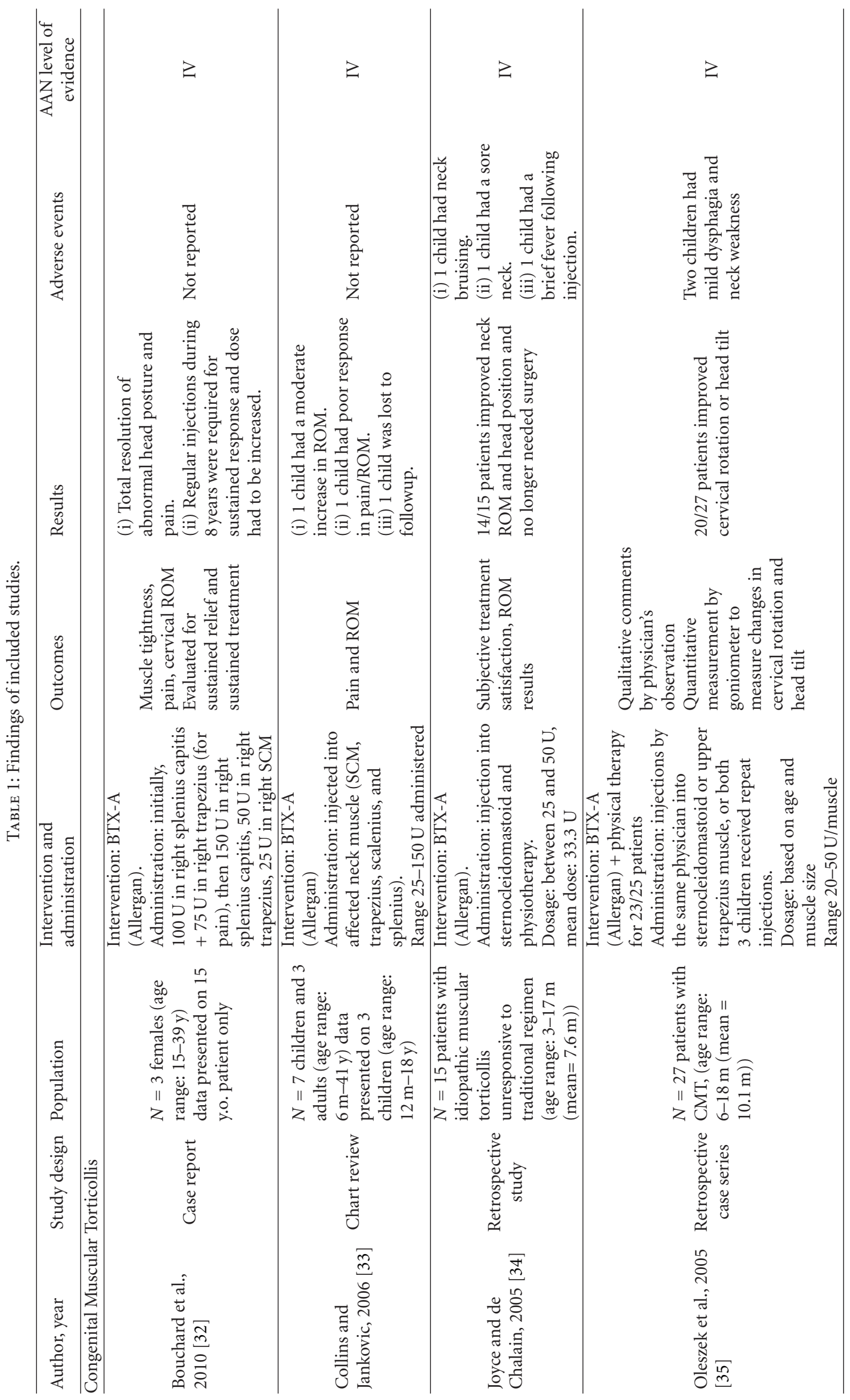




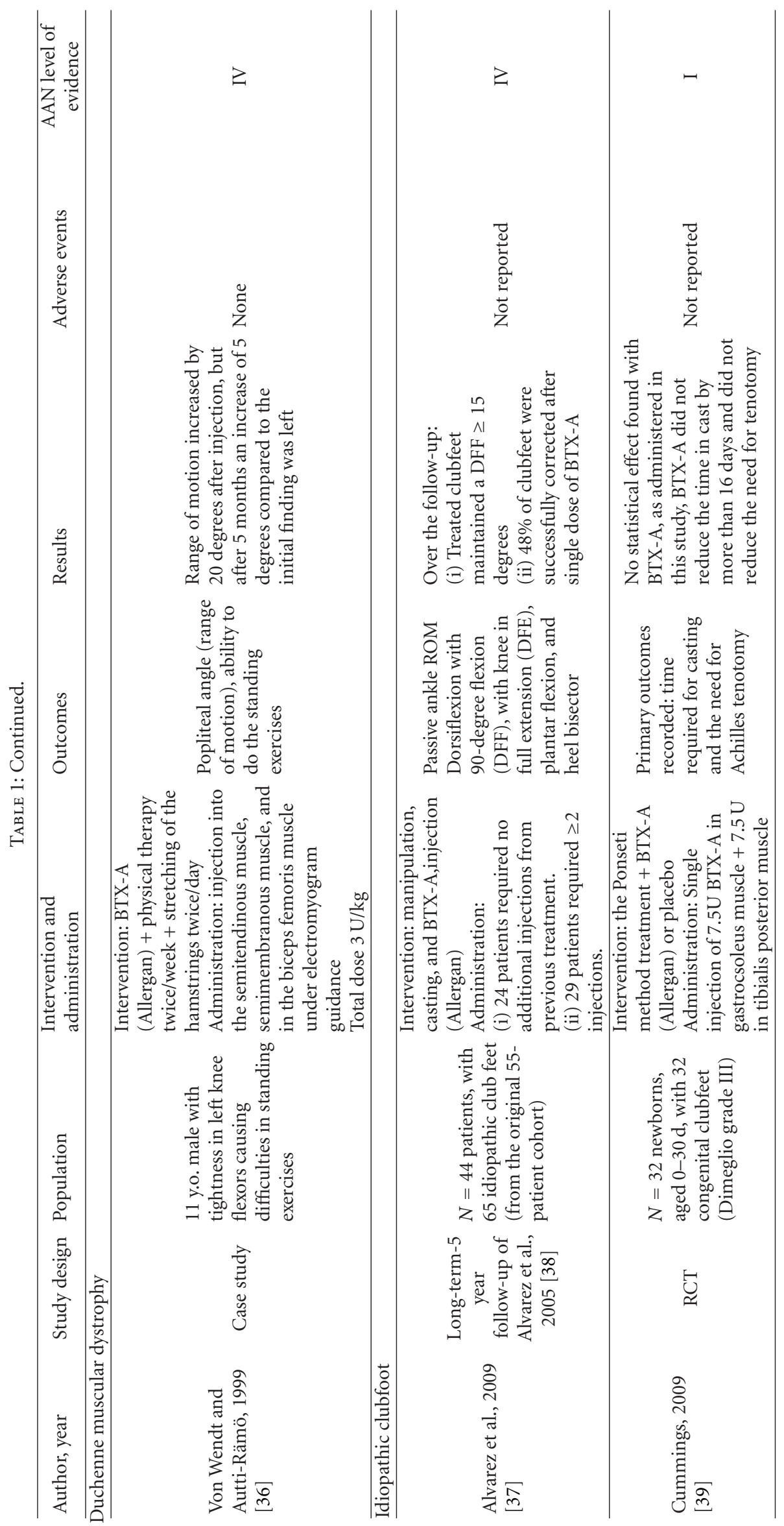




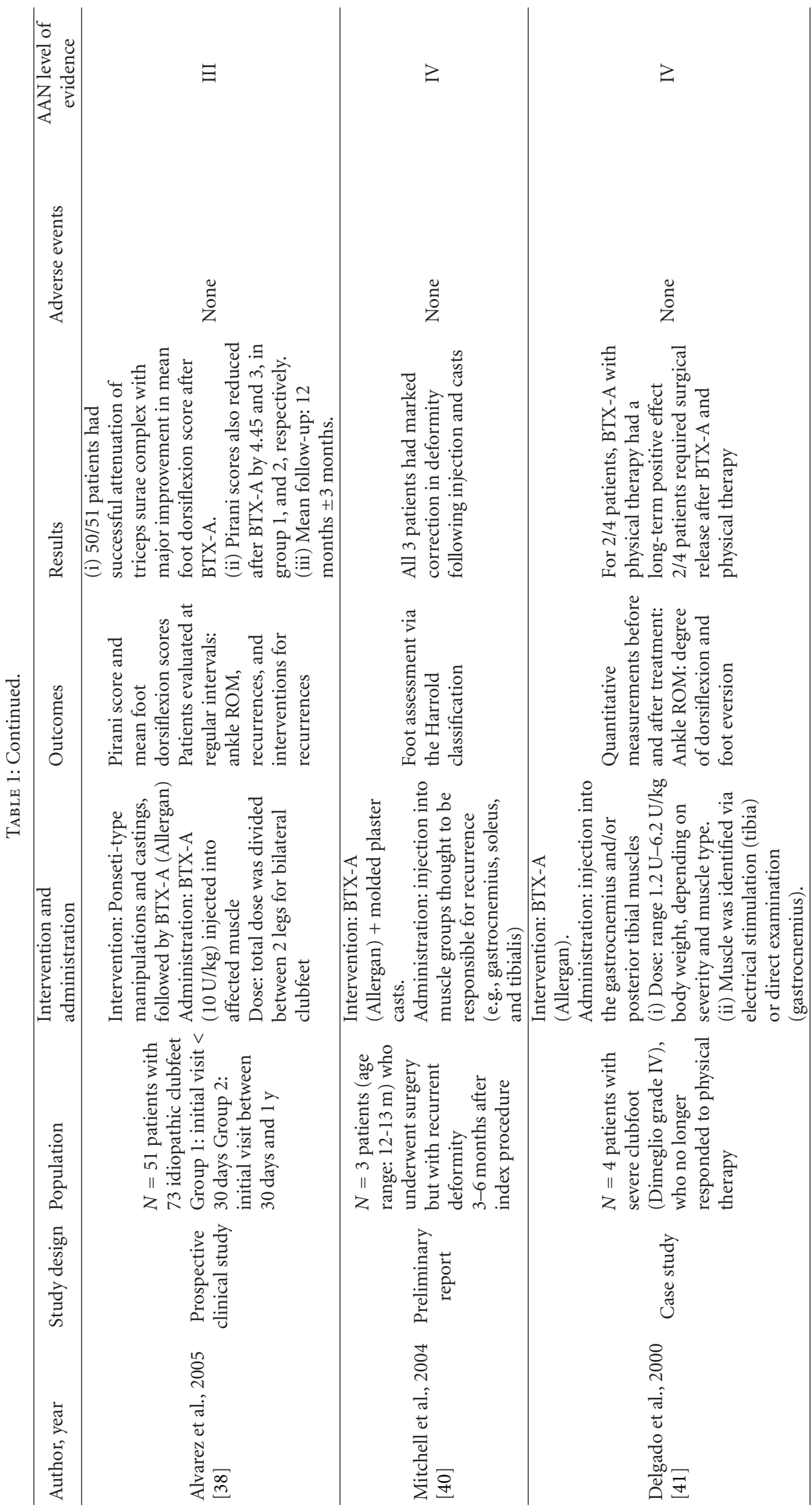




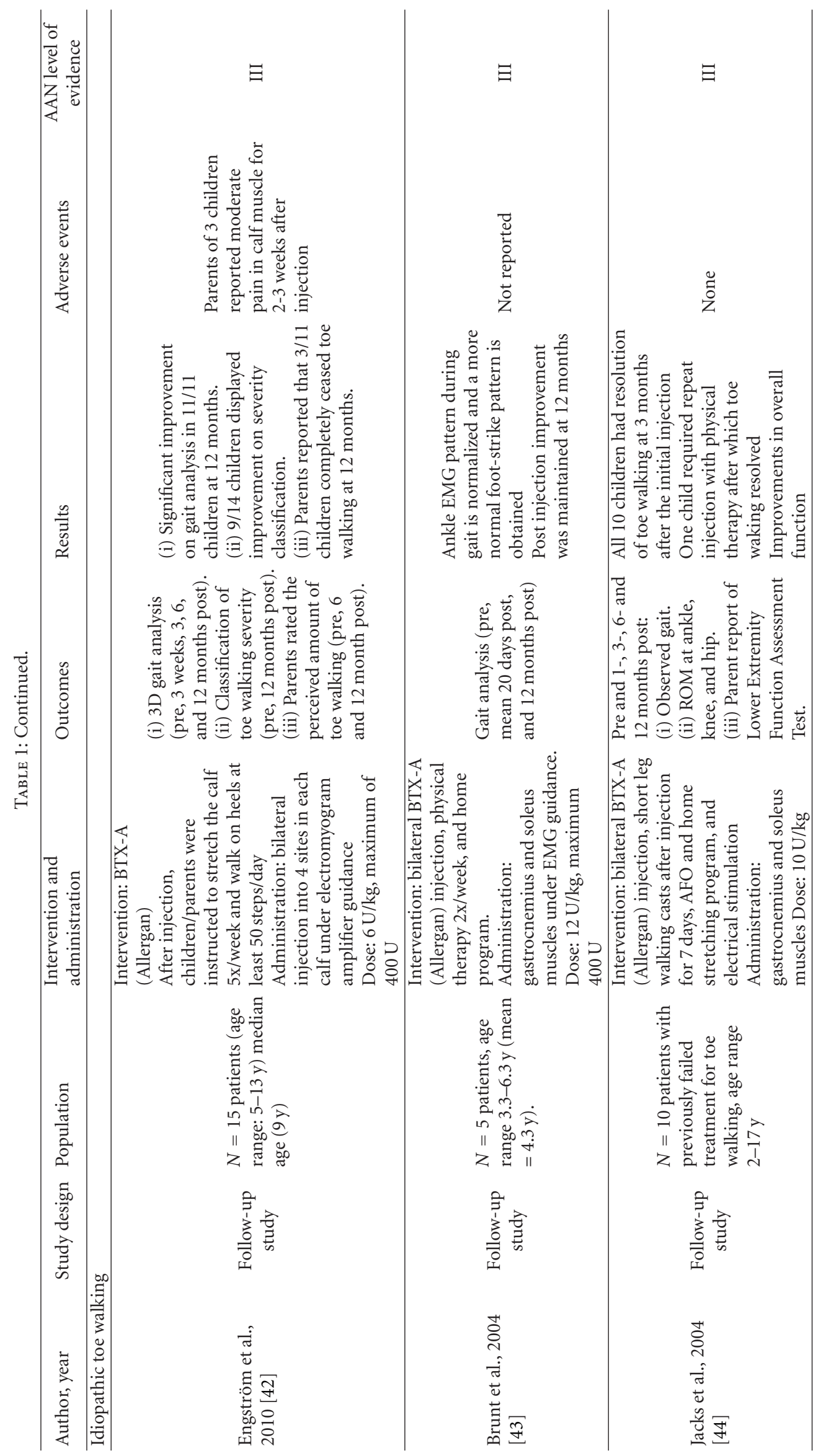




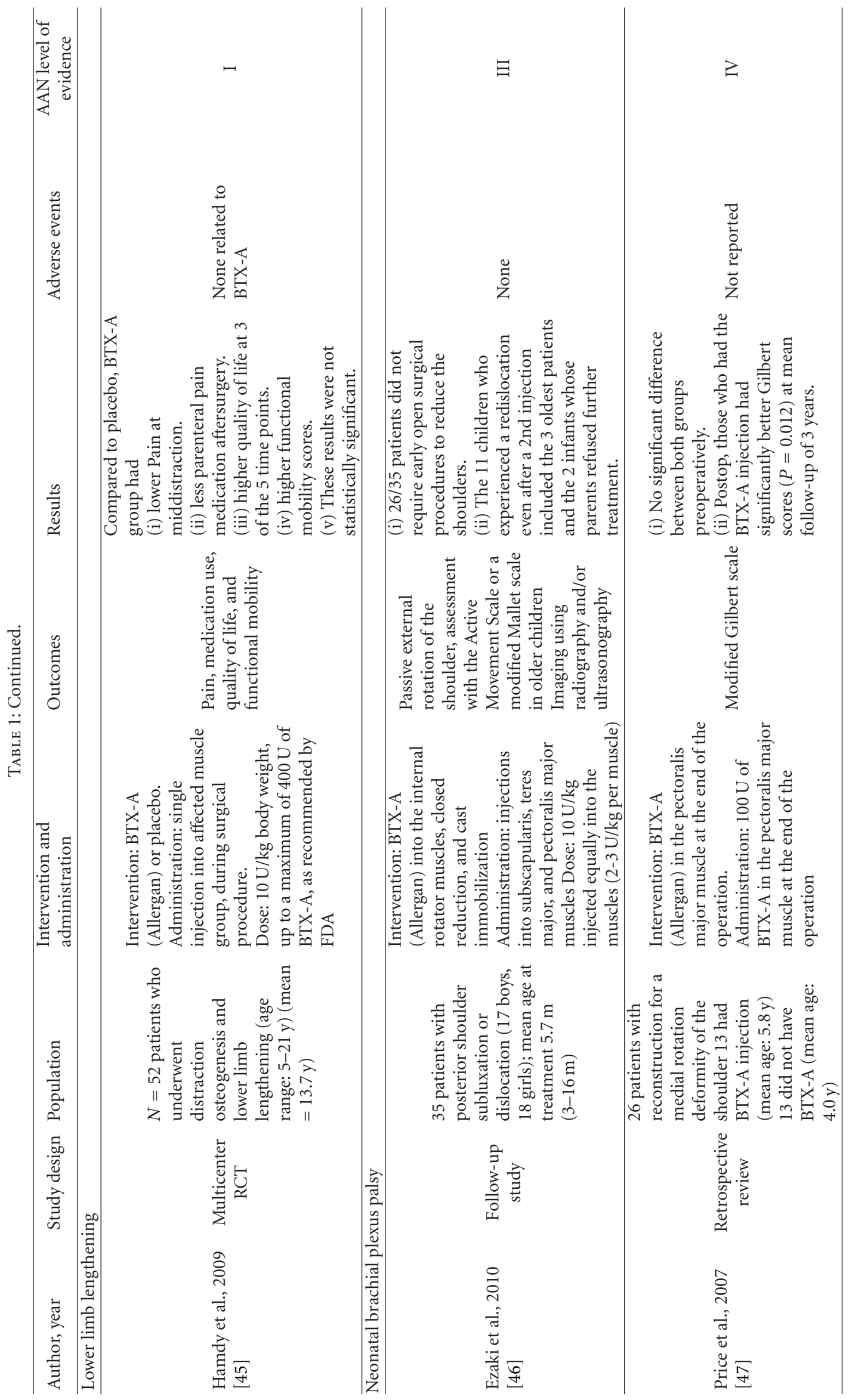




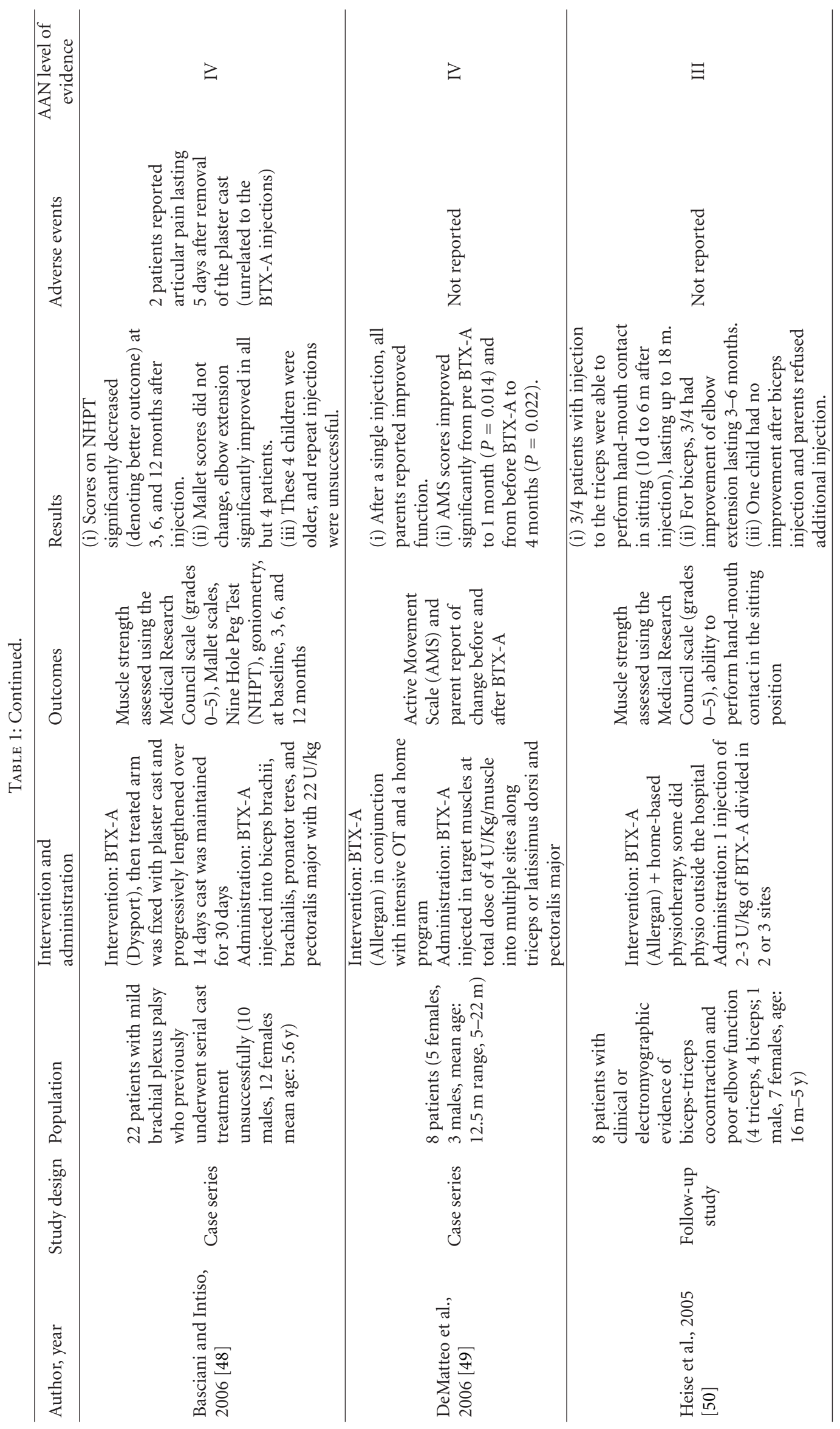




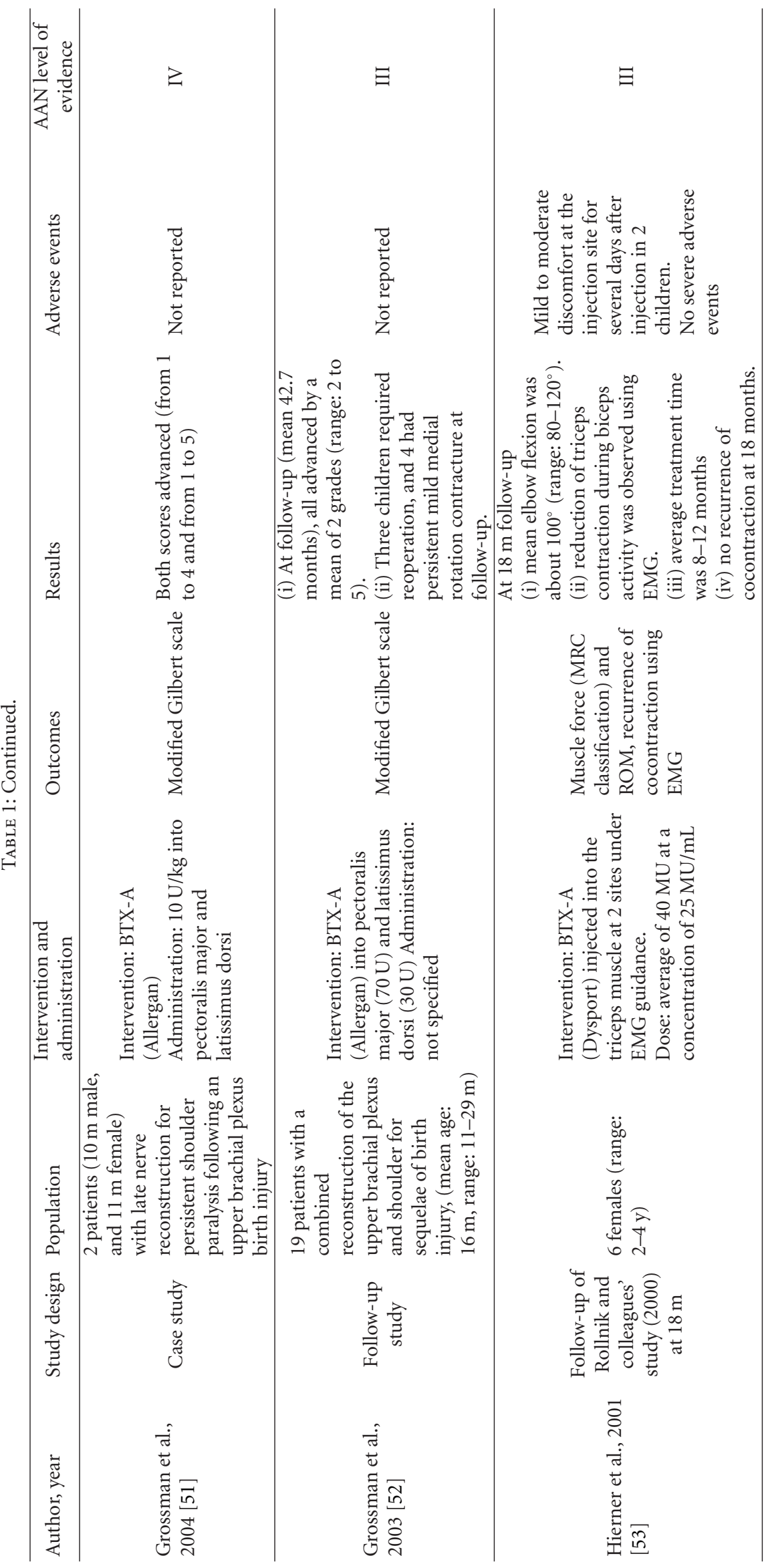




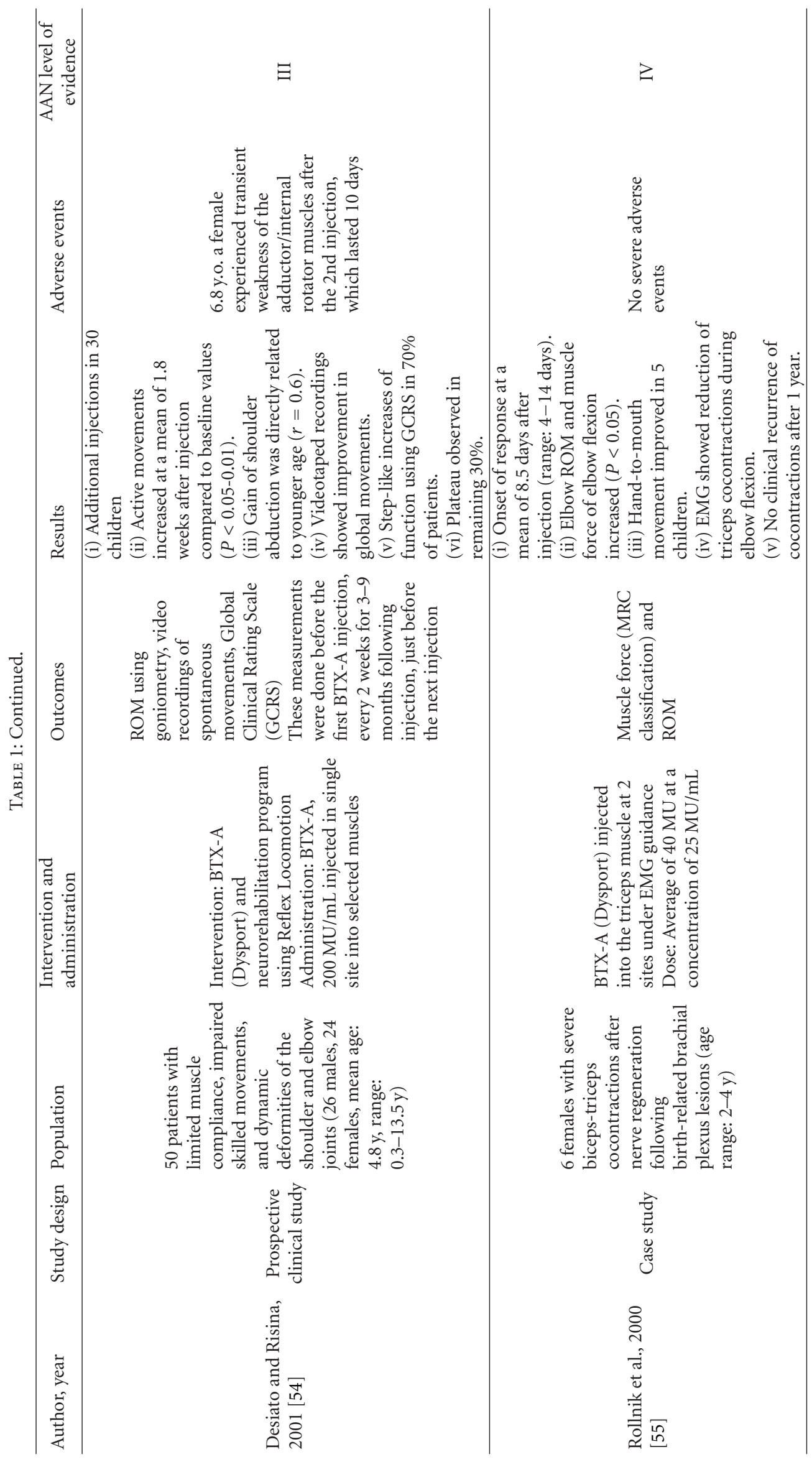


with BTX-A for tightness in the left knee flexors in order to enable standing exercises. Knee range of motion was increased by 20 degrees following injection, with no sideeffects. The child's posture in the standing frame was controlled more easily. The knee range of motion decreased by 15 degrees at 5 months after injection. BTX-A may be indicated in children with Duchenne muscular dystrophy when temporary improvement of range of motion is needed to minimize knee contracture and encourage exercises for muscle stretching, prevention of osteoporosis, and retaining lung function.

3.4. Idiopathic Clubfoot. Five articles were included. The first study by Delgado and colleagues [41] included four patients who had severe clubfoot deformities and rapidly reached a plateau following physical therapy. BTX-A injections helped most of the patients, despite their severe deformity, allowing two of them to avoid surgery. The remaining two patients had a demyelinating neuropathy and did not respond to BTX-A treatment. Another study by Mitchell and colleagues [40] reported on three children under the age of 13 months who had a recurrence of their deformity after surgery and found a marked improvement of the deformity following BTX-A injection and application of molded plaster casts. The largest study by Alvarez and colleagues [37,38] included 51 children. Following Ponseti-type manipulations, casting, and BTX-A injection, all but one child improved in terms of dorsiflexion and a decrease in the severity of the deformity was noted. Bracing was provided to maintain the correction. At the five-year follow-up visit, 48\% (31 of 65 clubfeet) successfully responded to a single BTX-A injection and experienced no recurrence over the follow-up period. At least one repeat BTX-A injection was required in 34 clubfeet, and surgery was required in 10 clubfeet. These four studies found a positive effect of BTX-A as an adjunct to manipulation, casting, and physical therapy to correct muscle imbalance and to correct recurrent deformity in idiopathic clubfoot. All five studies concluded that BTX-A may be an effective and safe treatment alternative and can decrease the number of patients requiring surgery. A limitation of these four studies is that they did not include a control group and that the results cannot be attributed solely to BTX-A as other treatment modalities were used. Cummings and colleagues [39] conducted a randomized double-blind controlled trial on 20 infants (32 clubfeet) comparing a single BTX-A injection to placebo following serial manipulation and casting according to the Ponseti technique. The study found no significant difference in time of correction, need for tenotomy, or relapse between both groups. However, this trial included a small sample size and low BTX-A dosage that may have compromised positive findings of BTX-A. No adverse events were reported following BTX-A injections in children with clubfoot. In order to address the need for additional BTX-A injections, a larger trial is required with regular follow-up as well as a good maintenance-bracing program, so as to provide each child with an individualized treatment. The exact dose and number of injections have not been established and may vary among individuals.
3.5. Idiopathic Toe Walking. Three studies [42-44] reported improvement in gait pattern, function, and decreased toe walking severity following BTX-A injection to gastrocnemius and soleus muscles. Improvements were maintained at 12 months. In addition to the BTX-A injection, children also received a home exercise program, physical therapy, and orthotics. Further studies are needed to evaluate whether repeated injections and BTX treatment in combination with other treatment interventions (such as orthotics and physical therapy) improve outcome.

3.6. Legg-Calvé-Perthes Disease. No studies were found.

3.7. Lower Limb Lengthening. One study [45] met the inclusion criteria. This was a pilot randomized controlled trial comparing the effects of BTX-A injection versus placebo at the time of surgery. Fifty-two children with limb length discrepancies of various etiologies, as well as children with surgical correction of clubfoot deformities, were included. Findings showed that compared to placebo, the BTX-A group had a trend for lower pain at middistraction, less parenteral pain medication after-surgery, higher functional mobility scores, and better quality of life at three of five time points, although these differences were not statistically significant. No adverse events related to the BTX-A injection were reported, indicating that BTX-A may be safe and effective in alleviating pain, improving functional mobility and quality of life in children undergoing lower limb lengthening and/or deformity correction. Future studies with larger sample sizes are required and with homogeneous study populations to verify whether BTX-A injections are beneficial at the time of surgery in these children.

3.8. Neonatal Brachial Plexus Palsy. Ten studies [46-55] reported on the outcomes of using BTX-A, in which one study by Hierner and colleagues [53] was a follow-up report of the previous study by Rollnik and colleagues [55]. Although all children were diagnosed with NBPP, there were a number of variations between studies in the specific mechanism of injury and in the underlying limitations, such as in severity of biceps-triceps cocontractions, persistence in shoulder paralysis, medial rotation deformity of the shoulder, response to serial cast treatment, and posterior shoulder subluxation or dislocation. The most commonly injected muscles were pectoralis major, latissimus dorsi, and triceps. However, different muscle injection sites were used across the studies, indicating an individualized protocol according to each child's condition and needs. Four studies reported administering additional BTX-A injections, as needed. All ten studies reported positive outcomes following BTX-A injections, including improved ability to make hand-tomouth movements, avoidance of open surgical procedures, improved active shoulder abduction and elbow extension, better functional scores, and reduction of triceps cocontractions during elbow flexion. Two studies $[46,48]$ reported that those children who did not experience improved outcomes following BTX-A injections were older. Desiato and Risina [54] found that the gain in shoulder abduction was directly 
related to younger age $(r=0.6)$. Transient weakness was reported in a 6-year-old female [54] and mild to moderate discomfort at the injection site was reported in two children [53]. Four studies reported no severe adverse event related to the BTX-A injections. Adverse events were not reported in four studies. These findings indicate that BTX-A may be a promising treatment modality in young children with NBPP; however, stronger methodologies are required to confirm the effectiveness of BTX-A for this condition.

\section{Discussion}

The objectives of this systematic review were to establish the evidence on the effectiveness of BTX-A in several musculoskeletal conditions in children and to show whether these studies reported improved functional outcome. Out of the 24 studies reviewed, only two randomized clinical trials were conducted, one in children with clubfeet [39] and the other in children undergoing lower limb lengthening [45]. Most studies were case studies with small sample sizes and no control group. Furthermore, treatment of children with musculoskeletal conditions is often multimodal, including bracing, casting, rehabilitation, and home programs. Therefore, attributing the improvements in outcome to a single intervention, such as BTX-A, is not straightforward.

A recent systematic review on the indications for the use of BTX-A treatment for children with NBPP was conducted by Gobets and colleagues [56]. They included 10 full-text papers and six congress abstracts, involving 343 children. Four groups of indications were identified: internal rotation/adduction contracture of the shoulder, limited active elbow flexion, limited active elbow extension, and pronation contracture of the lower arm. Overall, positive results were reported for all except the indication for limited active elbow extension. However, only one study was comparative in nature; all others were classified as having a low level of evidence. There was a large variation in outcome measures. These authors conclude that multicentre randomized controlled trials are needed to provide better evidence of BTX-A in this population.

Several factors specific to BTX-A injections may produce inter- and intrastudy variations. These factors include the different dosages and commercial sources of BTX-A used across the different studies. Two brands of BTX-A were used across the 24 studies (Allergan and Dysport). BTXA brand was not always specified in the reviewed studies and this information was made available in several cases by contacting the authors. These two preparations should not be used interchangeably, either in terms of predicting outcome or in determining doses to be used. Though the units are not interchangeable, various published reports support a conversion ratio from $1: 5$ to $1: 3$. The technique used to identify which muscle groups will be injected also varied (palpation technique, electrical stimulation, etc.). Indeed, different studies have used different techniques and thus may lead to varying outcomes following BTX-A injection. There is no consensus as to the exact age at which a child with a musculoskeletal condition should be first administered
BTX-A. Age of injection varied across the different studies reviewed. However, several authors [46, 48, 54] found that the younger children at the onset of BTX-A treatment for NBPP benefited most compared to older children. Another factor to keep in mind is the need for administering repeat BTX-A injections for sustained benefit. Some authors administered repeated BTX-A doses, whereas other authors gave just one dose, even in cases when the children did not demonstrate improved outcome following the initial BTXA injection. This may have been due to financial and time restrictions as repeated injections are both expensive and time-consuming. Findings indicate that repeat BTX-A doses appear safe in children with musculoskeletal conditions. Length of follow-up differed across studies. Longer follow-up periods are required to inform health care providers whether the benefits of BTX-A are temporary and transient and, then if indicated, at which time should an additional injection be administered. Alvarez and colleagues [37] conducted a 5 -year follow-up of their original study [38]. They reported that $48 \%$ of clubfeet were successfully corrected after a single dose of BTX-A in 44 children. This was the longest follow-up period among all the studies reviewed.

Serious adverse events related to BTX-A injection were not reported in the studies included in this review. Minor adverse events such as transient muscular weakness and local discomfort at the injection site were reported in few studies. While this may be suggestive of the clinical safety of BTX-A, it is important to note that several studies did not actually report on the presence or absence of adverse events. Therefore, more rigor is required in reporting these events to establish the safety of BTX-A in children with musculoskeletal conditions.

\section{Conclusions}

BTX-A is a promising treatment adjunct in improving functional outcomes in children with musculoskeletal conditions by causing a flaccid paralysis of the affected muscles. Further studies should include a prospective methodology, longer follow-up periods, and comparison group and evaluate whether repeated injections are required to improve the outcome of children, thus providing evidence on the effectiveness and safety of this drug in children with musculoskeletal conditions.

\section{Authors' Contributions}

R. Hamdy and N. Dahan-Oliel designed the review. N. Dahan-Oliel and B. Kasaai carried out the systematic review and data extraction. K. Montpetit participated in the methodology and clinical relevance and helped draft the manuscript. All authors read and approved the final paper.

\section{Conflict of Interests}

The authors declare that they have no competing interests. 


\section{Acknowledgment}

Thanks are extended to Guylaine Bédard from the medical illustrations department for her assistance.

\section{References}

[1] National Center for Health Statistics, National Ambulatory Medical Care Survey, 2003.

[2] National Center for Health Statistics, National Hospital Discharge Survey, 2003.

[3] B. J. Hoare, M. A. Wallen, C. Imms, E. Villanueva, H. B. Rawicki, and L. Carey, "Botulinum toxin A as an adjunct to treatment in the management of the upper limb in children with spastic cerebral palsy (UPDATE)," Cochrane Database of Systematic Reviews, no. 3, 2010.

[4] M. B. Lukban, R. L. Rosales, and D. Dressler, "Effectiveness of botulinum toxin A for upper and lower limb spasticity in children with cerebral palsy: a summary of evidence," Journal of Neural Transmission, vol. 116, no. 3, pp. 319-331, 2009.

[5] L. A. Koman, B. P. Smith, and R. Balkrishnan, "Spasticity associated with cerebral palsy in children: guidelines for the use of botulinum A toxin," Pediatric Drugs, vol. 5, no. 1, pp. 11-23, 2003.

[6] M. Brin and K. Aoki, "Botulinum toxin type A: pharmacology," in Spasticity, Etiology, Evaluation, Management and the Role of Botulinum Toxin, N. Mayer and D. Simpson, Eds., p. 111, We Move Worldwide Education, New York, NY, USA, 2002.

[7] M. Brin and K. Aoki, "Botulinum toxin type A: pharmacology," in Spasticity, Etiology, Evaluation, Management and the Role of Botulinum Toxin, N. Mayer and D. Simpson, Eds., pp. 110-124, We Move Worldwide Education, New York, NY, USA, 2005.

[8] J. Tsui, A. Eisen, E. Mak, M. Carruthers, A. Scott, and D. Calne, "A pilot study on the use of botuinum toxin in spasmodic torticolis," Canadian Journal Neurological Sciences, vol. 12, pp. 314-316, 1985.

[9] H. Schaible, G. Segond von Banchet, A. Ebersberger, and G. Natura, "Involvement of CGRP in nociceptive processing and hyperalgesia: effects on spinal and dorsal root ganglion neurons," in Hyperalgesia: Molecular Mechanisms and Clinical Implications, K. Brune and H. Handwerker, Eds., Progress in Pain Research and Management, pp. 201-228, Seattle, Wash, USA, 2004.

[10] G. E. Francisco, "Botulinum toxin: dosing and dilution," American Journal of Physical Medicine and Rehabilitation, vol. 83, supplement 10, pp. S30-S37, 2004.

[11] A. M. O. Bakheit, "Botulinum toxin in the management of childhood muscle spasticity: comparison of clinical practice of 17 treatment centres," European Journal of Neurology, vol. 10, no. 4, pp. 415-419, 2003.

[12] M. Ramachandran and D. M. Eastwood, "Botulinum toxin and its orthopaedic applications," Journal of Bone and Joint Surgery, vol. 88, no. 8, pp. 981-987, 2006.

[13] A. Alberto, "Terminology for preparations of botulinum neurotoxins: what a difference a name makes," Journal of the American Medical Association, vol. 305, no. 1, pp. 89-90, 2011.

[14] T. M. Seyler, B. P. Smith, D. R. Marker et al., "Botulinum neurotoxin as a therapeutic modality in orthopaedic surgery: more than twenty years of experience," Journal of Bone and Joint Surgery, vol. 90, no. 4, pp. 133-145, 2008.
[15] K. Lowe, I. Novak, and A. Cusick, "Repeat injection of botulinum toxin A is safe and effective for upper limb movement and function in children with cerebral palsy," Developmental Medicine and Child Neurology, vol. 49, no. 11, pp. 823-829, 2007.

[16] G. Molenaers, A. van Campenhout, K. Fagard, J. de Cat, and K. Desloovere, "The use of botulinum toxin A in children with cerebral palsy, with a focus on the lower limb," Journal of Children's Orthopaedics, vol. 4, no. 3, pp. 183-195, 2010.

[17] M. R. Delgado, D. Hirtz, M. Aisen et al., "Practice parameter: pharmacologic treatment of spasticity in children and adolescents with cerebral palsy (an evidence-based review): report of the Quality Standards Subcommittee of the American Academy of Neurology and the Practice Committee of the Child Neurology Society," Neurology, vol. 74, no. 4, pp. 336$343,2010$.

[18] R. Aoki and K. Martin, "Pharmacology in pain relief," in Botulinum Toxin Type A In Pain Management. A Clinician's Guide, M. K. Childers, Ed., pp. 31-40, Academic Information Systems, 2nd edition, 2002.

[19] S. J. O'flaherty, V. Janakan, A. M. Morrow, A. M. Scheinberg, and M. A. Waugh, "Adverse events and health status following botulinum toxin type A injections in children with cerebral palsy," Developmental Medicine and Child Neurology, vol. 53, no. 2, pp. 125-130, 2011.

[20] N. H. Robin, "Congenital muscular torticollis," Pediatrics in Review, vol. 17, no. 10, pp. 374-375, 1996.

[21] S. S. Freed and C. Coulter-O'Berry, "Identification and treatment of congenital muscular torticollis in infants," Journal of Prosthetics and Orthotics, vol. 16, supplement 4, pp. S18-S23, 2004.

[22] B. L. Luther, "Congenital muscular torticollis," Orthopaedic Nursing, vol. 21, no. 3, pp. 21-27, 2002.

[23] V. Dubowitz, "The muscular dystrophies," in Muscle Disorders in Childhood, pp. 34-133, WB Saunders, London, UK, 1995.

[24] S. J. Laaveg and I. V. Ponseti, "Long-term results of treatment of congenital clubfoot," Journal of Bone \& Joint Surgery, vol. 62, pp. 23-31, 1980.

[25] I. V. Ponseti, Congenital Clubfoot: Fundamentals of Treatment, Oxford University Press, New York, NY, USA, 1996.

[26] R. Engelbert, J. W. Gorter, C. Uiterwaal, E. Van De Putte, and P. Helders, "Idiopathic toe-walking in children, adolescents and young adults: a matter of local or generalised stiffness?" BMC Musculoskeletal Disorders, vol. 12, article 61, 2011.

[27] M. Nelitz, S. Lippacher, R. Krauspe, and H. Reichel, "Perthes disease: current principles of diagnosis and treatment," Deutsches Arzteblatt, vol. 106, no. 31-32, pp. 517-523, 2009.

[28] G. De Bastiani, R. Aldegheri, L. Renzi-Brivio, and G. Trivella, "Limb lengthening by callus distraction (callotasis)," Journal of Pediatric Orthopaedics, vol. 7, no. 2, pp. 129-134, 1987.

[29] N. Maffulli, C. Lombari, L. Matarazzo, U. Nele, G. Pagnotta, and J. A. Fixsen, "A review of 240 patients undergoing distraction osteogenesis for congenital post-traumatic or postinfective lower limb length discrepancy," Journal of the American College of Surgeons, vol. 182, no. 5, pp. 394-402, 1996.

[30] D. I. Zafeiriou and K. Psychogiou, "Obstetrical brachial plexus palsy," Pediatric Neurology, vol. 38, no. 4, pp. 235-242, 2008.

[31] J. Bahm, M. Becker, C. Disselhorst-Klug, S. Williams, L. Meinecke, H. Müller et al., "Surgical strategy in obstetric brachial plexus palsy: the aachen experience," Seminars in Plastic Surgery, vol. 18, pp. 285-299, 2004.

[32] M. Bouchard, S. Chouinard, and A. O. Suchowersky, "Adult cases of congenital muscular torticollis successfully treated 
with botulinum toxin," Movement Disorders, vol. 25, no. 14, pp. 2453-2456, 2010.

[33] A. Collins and J. Jankovic, "Botulinum toxin injection for congenital muscular torticollis presenting in children and adults," Neurology, vol. 67, no. 6, pp. 1083-1085, 2006.

[34] M. B. Joyce and T. M. B. de Chalain, "Treatment of recalcitrant idiopathic muscular torticollis in infants with botulinum toxin type A," Journal of Craniofacial Surgery, vol. 16, no. 2, pp. 321327, 2005.

[35] J. L. Oleszek, N. Chang, S. D. Apkon, and P. E. Wilson, "Botulinum toxin type A in the treatment of children with congenital muscular torticollis," American Journal of Physical Medicine and Rehabilitation, vol. 84, no. 10, pp. 813-816, 2005.

[36] L. O. Von Wendt and I. S. Autti-Rämö, "Botulinum toxin for amelioration of knee contracture in Duchenne muscular dystrophy," European Journal of Paediatric Neurology, vol. 3, no. 4, pp. 175-176, 1999.

[37] C. M. Alvarez, M. A. De Vera, H. Chhina, L. Williams, K. Durlacher, and S. Kaga, "The use of botulinum type A toxin in the treatment of idiopathic clubfoot: 5-Year follow-up," Journal of Pediatric Orthopaedics, vol. 29, no. 6, pp. 570-575, 2009.

[38] C. M. Alvarez, S. J. Tredwell, S. P. Keenan et al., "Treatment of idiopathic clubfoot utilizing botulinum A toxin: a new method and its short-term outcomes," Journal of Pediatric Orthopaedics, vol. 25, no. 2, pp. 229-235, 2005.

[39] R. J. Cummings, "The effectiveness of botulinum A toxin as an adjunct to the treatment of clubfeet by the Ponseti method: a randomized, double blind, placebo controlled study," Journal of Pediatric Orthopaedics, vol. 29, no. 6, pp. 564-569, 2009.

[40] P. D. Mitchell, M. Tisdall, and H. G. Zadeh, "Selective botulinum toxin injection in the treatment of recurrent deformity following surgical correction of club foot: a preliminary report of 3 children," Acta Orthopaedica Scandinavica, vol. 75, no. 5, pp. 630-633, 2004.

[41] M. R. Delgado, H. Wilson, C. Johnston, S. Richards, and L. Karol, "A preliminary report of the use of botulinum toxin type A in infants with clubfoot: four case studies," Journal of Pediatric Orthopaedics, vol. 20, no. 4, pp. 533-538, 2000.

[42] P. Engström, E. M. Gutierrez-Farewik, Å. Bartonek, K. Tedroff, C. Orefelt, and Y. Haglund-Åkerlind, "Does botulinum toxin A improve the walking pattern in children with idiopathic toewalking?" Journal of Children's Orthopaedics, vol. 4, no. 4, pp. 301-308, 2010.

[43] D. Brunt, R. Woo, H. D. Kim, M. S. Ko, C. Senesac, and S. $\mathrm{Li}$, "Effect of botulinum toxin type A on gait of children who are idiopathic toe-walkers," Journal of Surgical Orthopaedic Advances, vol. 13, no. 3, pp. 149-155, 2004.

[44] L. K. Jacks, D. M. Michels, B. P. Smith, L. A. Koman, and J. Shilt, "Clinical usefulness of botulinum toxin in the lower extremity," Foot and Ankle Clinics, vol. 9, no. 2, pp. 339-348, 2004.

[45] R. C. Hamdy, K. Montpetit, E. M. Raney et al., "Botulinum toxin type a injection in alleviating postoperative pain and improving quality of life in lower extremity limb lengthening and deformity correction: a pilot study," Journal of Pediatric Orthopaedics, vol. 29, no. 5, pp. 427-434, 2009.

[46] M. Ezaki, K. Malungpaishrope, R. J. Harrison et al., "OnabotulinumtoxinA injection as an adjunct in the treatment of posterior shoulder subluxation in neonatal brachial plexus palsy," Journal of Bone and Joint Surgery, vol. 92, no. 12, pp. 2171-2177, 2010.

[47] A. E. Price, P. DiTaranto, I. Yaylali, M. A. Tidwell, and J. A. I. Grossman, "Botulinum toxin type A as an adjunct to the surgical treatment of the medial rotation deformity of the shoulder in birth injuries of the brachial plexus," Journal of Bone and Joint Surgery, vol. 89, no. 3, pp. 327-329, 2007.

[48] M. Basciani and D. Intiso, "Botulinum toxin type-A and plaster cast treatment in children with upper brachial plexus palsy," Pediatric Rehabilitation, vol. 9, no. 2, pp. 165-170, 2006.

[49] C. DeMatteo, J. R. Bain, V. Galea, and D. Gjertsen, "Botulinum toxin as an adjunct to motor learning therapy and surgery for obstetrical brachial plexus injury," Developmental Medicine and Child Neurology, vol. 48, no. 4, pp. 245-252, 2006.

[50] C. O. Heise, L. R. Gonçalves, E. R. Barbosa, and J. L. D. Gherpelli, "Botulinum toxin for treatment of cocontractions related to obstetrical brachial plexopathy," Arquivos de NeuroPsiquiatria, vol. 63, no. 3 A, pp. 588-591, 2005.

[51] J. A. I. Grossman, P. DiTaranto, I. Yaylali, I. Alfonso, L. E. Ramos, and A. E. Price, "Shoulder function following late neurolysis and bypass grafting for upper brachial plexus birth injuries," Journal of Hand Surgery, vol. 29, no. 4, pp. 356-358, 2004.

[52] J. A. I. Grossman, A. E. Price, M. A. Tidwell, L. E. Ramos, I. Alfonso, and I. Yaylali, "Outcome after later combined brachial plexus and shoulder surgery after birth trauma," Journal of Bone and Joint Surgery, vol. 85, no. 8, pp. 1166-1168, 2003.

[53] R. Hierner, J. D. Rollnik, A. C. Berger, and R. Dengler, "Botulinum toxin type a for the treatment of biceps/triceps cocontraction in obstetrical brachial plexus lesions. Preliminary results after a follow-up of 18 months," European Journal of Plastic Surgery, vol. 24, no. 1, pp. 2-6, 2001.

[54] M. T. Desiato and B. Risina, "The role of botulinum toxin in the neuro-rehabilitation of young patients with brachial plexus birth palsy," Pediatric Rehabilitation, vol. 4, no. 1, pp. 29-36, 2001.

[55] J. D. Rollnik, R. Hierner, M. Schubert et al., "Botulinum toxin treatment of cocontractions after birth-related brachial plexus lesions," Neurology, vol. 55, no. 1, pp. 112-114, 2000.

[56] D. Gobets, H. Beckerman, V. D. Groot, M. H. Van DoornLoogman, and J. G. Becher, "Indications and effects of botulinum toxin A for obstetric brachial plexus injury: a systematic literature review," Developmental Medicine and Child Neurology, vol. 52, no. 6, pp. 517-528, 2010. 


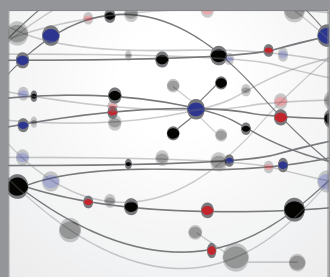

The Scientific World Journal
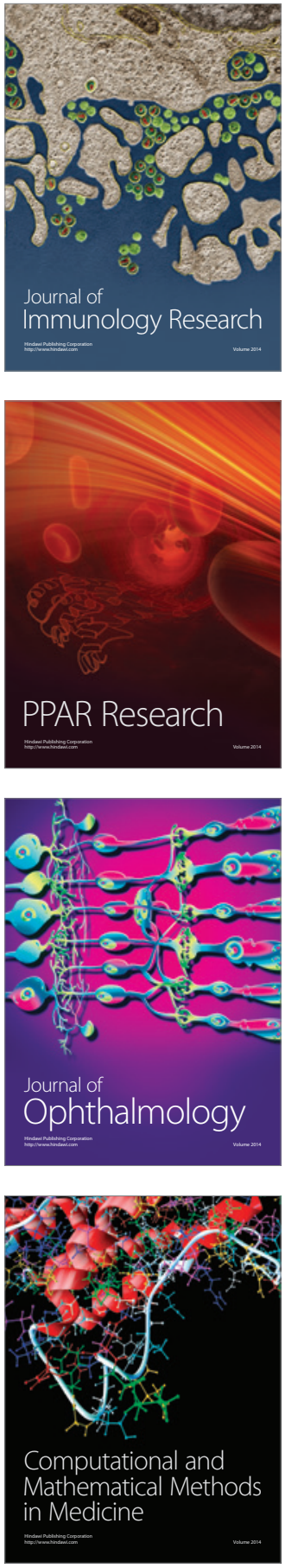

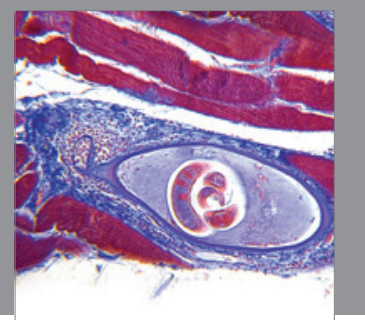

Gastroenterology

Research and Practice
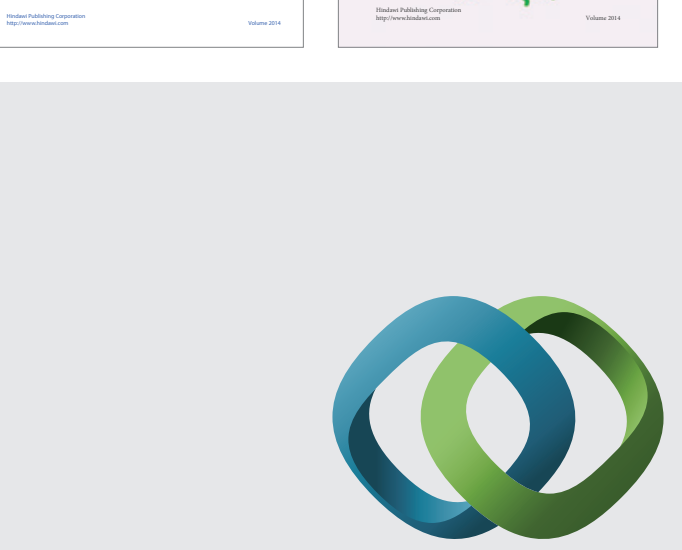

\section{Hindawi}

Submit your manuscripts at

http://www.hindawi.com
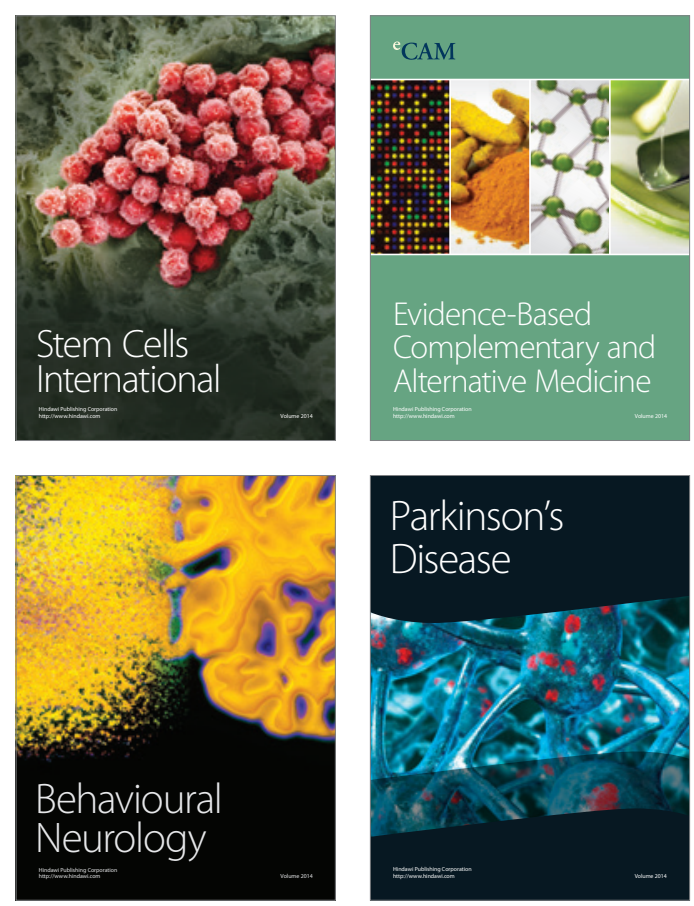

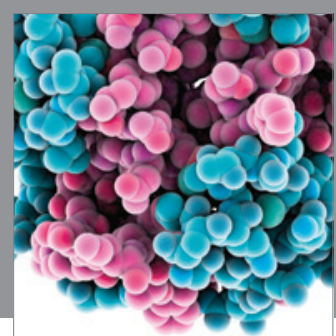

Journal of
Diabetes Research

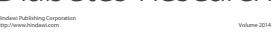

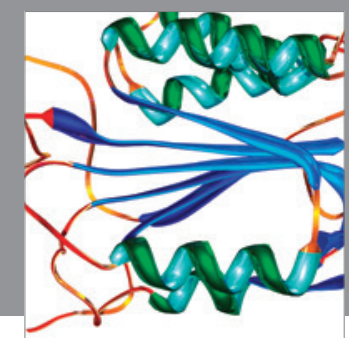

Disease Markers
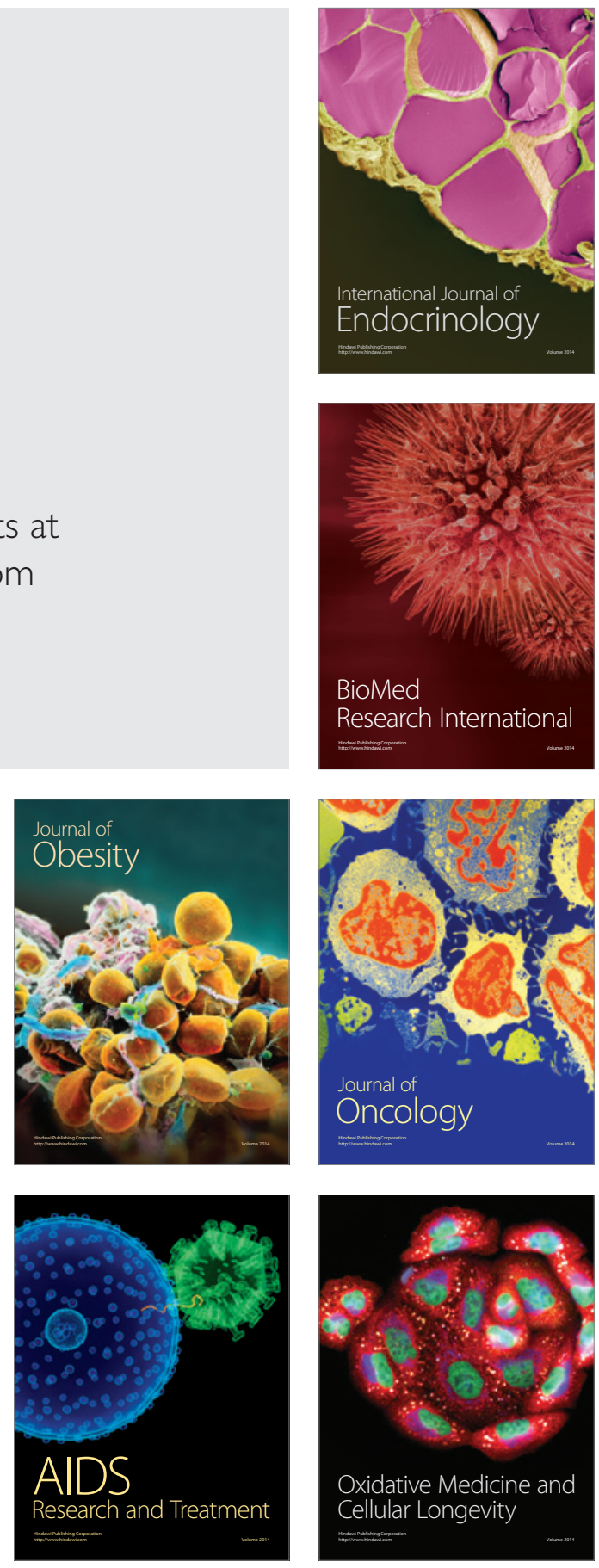